\title{
Semisolid Microstructure Evolution of AZ91D Magnesium Alloy Refined by Al-Ti-B
}

\author{
Ti Jun Chen*, Rui Quan Wang, Ying Ma, Yuan Hao \\ Key Laboratory of Gansu Advanced Nonferrous Metal Materials, \\ Lanzhou University of Technology - LUT, Lanzhou, 730050, China
}

Received: April 25, 2011; Revised: October 9, 2011

\begin{abstract}
The microstructural evolution and corresponding phase transformations have been investigated during partial remelting of AZ91D magnesium alloy refined by Al-Ti-B master alloy. The effect of heating temperature on semisolid microstructure has also been discussed. The results indicate that the microstructural evolution process includes four stages, the initial rapid coarsening, structure separation, spheroidization accompanied by coarsening and the final coarsening. Two or more equiaxed dendrites in the as-cast microstructure evolve into one spheroidal primary particle in the semisolid microstructure through the former three stages. The initial rapid coarsening results from the reaction of $\beta \rightarrow \alpha$, the structure separation is due to the $\alpha+\beta \rightarrow L$ and $\alpha \rightarrow L$, the spheroidization is attributed to the $\alpha \rightarrow \mathrm{L}$ and the final coarsening is ascribed to the two reverse reactions of $\alpha \rightarrow \mathrm{L}$ and $\mathrm{L} \rightarrow \alpha$. Rising the heating temperature during partial remelting is beneficial for obtaining small and spheroidal primary particles.
\end{abstract}

Keywords: AZ91D magnesium alloy, thixoforming, semisolid microstructure, phase transformation

\section{Introduction}

Magnesium alloys have relatively small density and high specific strength and stiffness, and thus are very attractive for structural applications in transportation industry ${ }^{1}$. However, mechanical properties of the same samples of most of the magnesium alloys are inferior to those of another family of light alloys, aluminum alloys, and do not meet the requirements in many situations. To improve their mechanical properties, as known, thixoforming is a promising way by decreasing grain size and shrinkage porosities ${ }^{2}$.

The origin of thixoforming is the semisolid microstructure with small and spheroidal primary particles uniformly suspended in liquid phase $^{2}$. There are many methods to obtain this kind of nondendritic semisolid microstructure, such as magnetohydrodynamic or mechanical stirring, spray casting, chemical grain refining, near-liquidus pouring and strain-induced melt activation ${ }^{2,3}$. Alternatively, the chemical grain refining process produces the desired microstructures by adding grain refiner during traditional casting and a following partial remelting. It is a relatively simple method because it does not need special treatments, such as stirring, spraying or deformation ${ }^{2,3}$. The key of this method is to prepare cast ingots with fine equiaxed grains. Unfortunately, for the most commonly-used magnesium alloy of AZ91D, there is still no a commercially-used grain refining technique ${ }^{4-6}$. The result from the authors' previous investigation indicates that its grain size can be decreased from $422 \mu \mathrm{m}$ to $79 \mu \mathrm{m}$ after being refined by an Al-Ti-B master alloy that has been commercially used to aluminium alloys ${ }^{7}$.

It is well known that the microstructural evolution during partial remelting is the key scientific topic for thixoforming because this process has large effect on the resultant semisolid microstructure. However, most of the existing investigations about magnesium alloys have been focused on some previously deformed alloys s,8-14 $^{2}$ Only a few papers have involved the as-cast alloys, but they all emphasized on the morphology change and coarsening behavior of primary particles in semisolid state ${ }^{15-21}$. It can be expected that, to verify how the equiaxed dendrites in as-cast microstructure evolve into the spheroidal solid particles in semisolid microstructure, the whole microstructural evolution, especially the microstructure change before liquid formation during particle remelting should be clarified. In addition, the microstructural evolution essentially results from phase transformations occurring during partial remelting. So the study on the phase transformations can offer some important information to verify the microstructural evolution process. But the existing investigations almost have not involved this aspect.

Therefore, in this work, the microstructural evolution has been investigated during partial remelting of AZ91D alloy refined by Al-Ti-B master alloy, especially the evolution process prior to liquid formation. Simultaneously, the phase transformations occurring during this process has been discussed. In addition, the effect of heating temperature on semisolid microstructure has also been studied.

\section{Experimental Procedure}

The material used in this work is commercial AZ91D alloy and its composition is $\mathrm{Mg}-9.04 \mathrm{Al}-0.6 \mathrm{Zn}-0.31 \mathrm{Mn}$ (the percentages in this paper all refer to weight percentage). The refiner is an Al-5Ti-1B master alloy that is commercially applied to aluminium alloys. A quantity of AZ91D alloy was first remelted under protection of RJ-2 flux. $0.3 \%$ master alloy then was added at $750{ }^{\circ} \mathrm{C}$ and the melt was held for 30 minutes. Following, the melt was cooled to $705^{\circ} \mathrm{C}$ and poured into a permanent mould with ambient temperature, and some rods with dimensions of $\Phi 16 \mathrm{mmX130} \mathrm{mm}$ were obtained.

The cast rods were cut into small specimens with height of $10 \mathrm{~mm}$. Some of them were heated at $580{ }^{\circ} \mathrm{C}$ in a resistant furnace under protection of RJ-2 flux for different durations and then water-quenched. To study the effect of heating temperature on semisolid microstructure, two specimens were heated for 30 minutes at 570 and $590{ }^{\circ} \mathrm{C}$ respectively and then also water-quenched. 
According to the Mg-Al binary phase diagram shown by Figure $1^{22}$, the temperatures employed in this work are all within the solidification interval of AZ91D alloy. To precisely control the temperatures, an intelligent temperature controller having an accuracy of $\pm 0.5{ }^{\circ} \mathrm{C}$ was used. Before a specimen was quickly put into the furnace, the furnace was held for 30 minutes at the given temperatures. The heated specimens were finished and polished according to standard metallographic technique. Then they were observed by a scanning electron microscope (SEM) using back-scattered imaging mode and examined by energy disperse spectroscopy (EDS). Subsequently, they were etched by an aqueous solution containing glycerol, nitric acid, hydrochloric acid and acetic acid and observed by an optical microscope (OM). The obtained OM images of some of semisolid microstructures were analyzed by Image-Pro Plus 5.0 software to calculate the primary particle size and shape factor. Three typical images with magnification of 100 times were examined for each specimen. To deduce the phase transformations during partial remelting, X-ray diffractometer (XRD) was used to verify phase constituents of the specimens heated for different durations at $580^{\circ} \mathrm{C}$.

\section{Results and Discussion}

\subsection{Microstructural evolution during partial remelting}

To clarify the microstructural evolution and phase transformations during partial remelting, the initial as-cast microstructure should be first verified. The unrefined AZ91D alloy has very developed dendrites and its average grain size is up to $422 \mu \mathrm{m}$ (Figure 2a) while the refined one by the Al-Ti-B master alloy is consisted of fine equiaxed dendrites with average size of $79 \mu \mathrm{m}$ (Figure $2 \mathrm{~b}$ ). The neighboring fine dendrites are separated by discontinuous eutectic $\beta$ phase while the neighboring dendrite arms within one dendrite are usually separated by eutectic $\alpha-\mathrm{Mg}$ phase, and occasionally a few of dot-like $\beta$ phase particles distribute between them (Figure 2c). That is to say that most of the eutectic $\beta$ phase distribute between the dendrites, not between the arms. In addition, the eutectic structures belong to devoiced eutectic. According to the equilibrium phase diagram of binary $\mathrm{Mg}-\mathrm{Al}$ shown by Figure $1^{22}$, it can be expected that the residual liquid amount is quite little during eutectic reaction because the $\mathrm{Al}$ content is far away from the Mg-Al binary eutectic point for AZ91D alloy. The liquid phase always distributes in thin layers or small-sized pools between

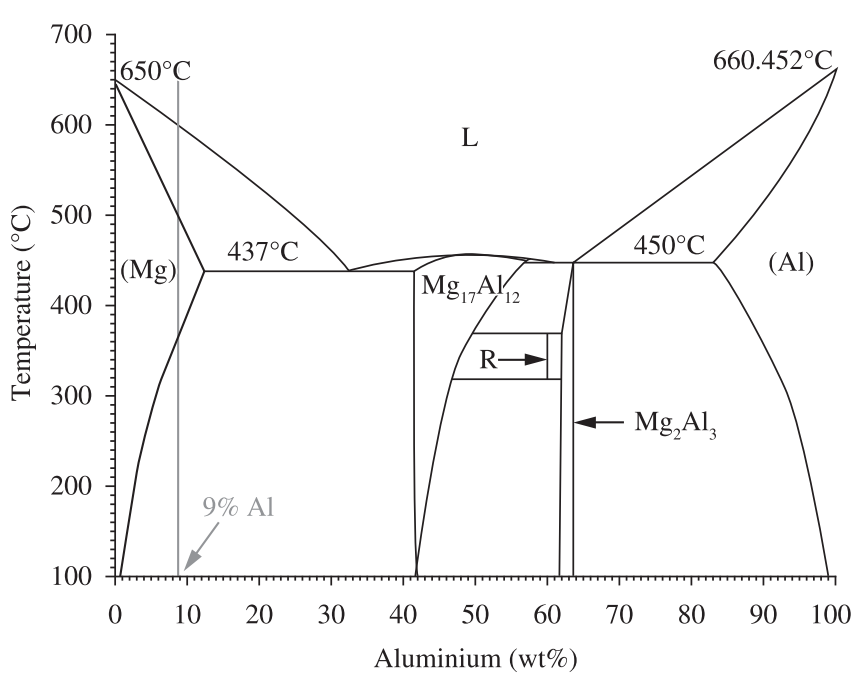

Figure 1. Mg-Al binary phase diagram ${ }^{22}$. the primary dendrites and between the arms, and thus the eutectic $\alpha$ phase always directly grows on the surfaces of primary dendrites without renucleation. Only the eutectic $\beta$ phase is left between the dendrites and between the arms.

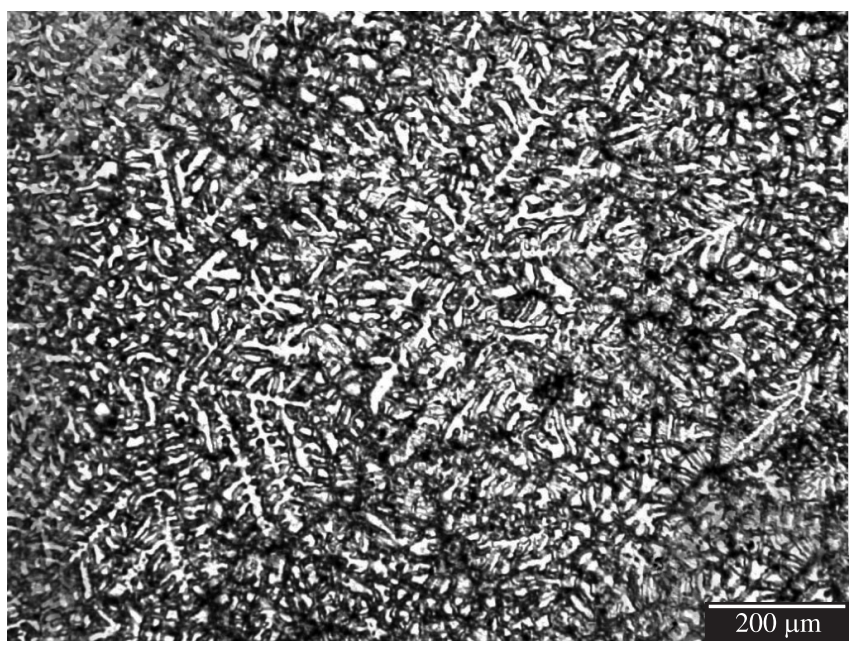

(a)

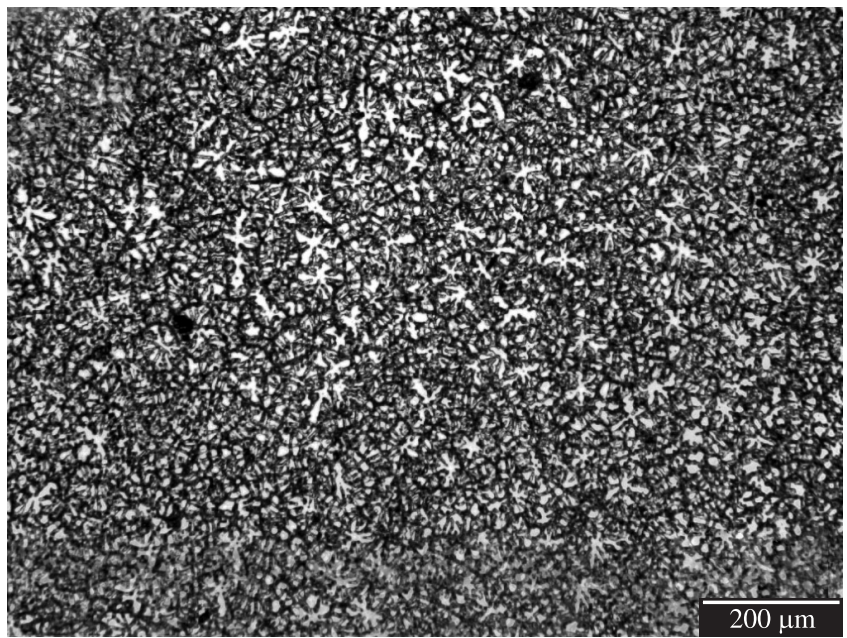

(b)

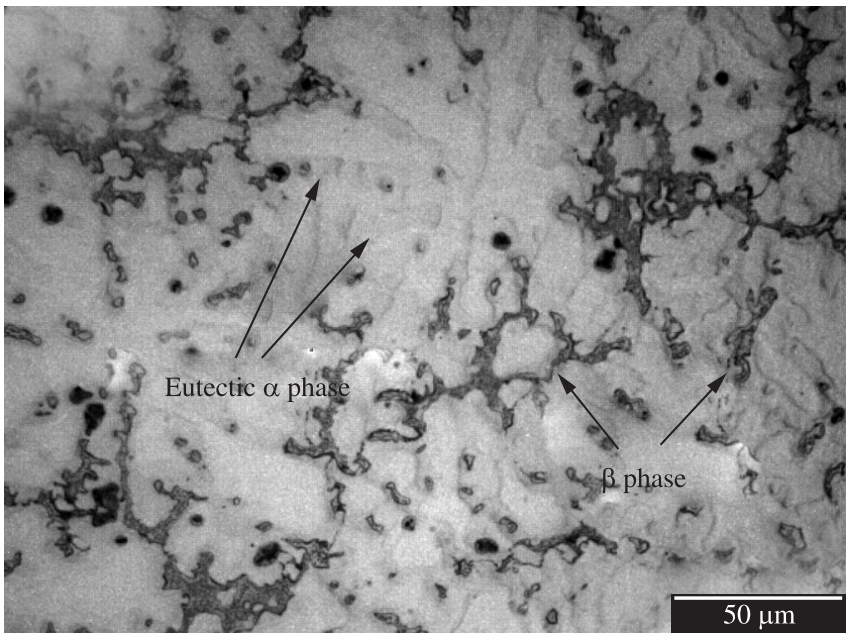

(c)

Figure 2. Microstructures of: a) unrefined; and b,c) refined ZA91D alloys. 
Figure 3 presents the SEM micrographs of the AZ91D alloys heated at $580{ }^{\circ} \mathrm{C}$ for different durations. According to the binary $\mathrm{Mg}-\mathrm{Al}$ phase diagram (Figure 1) ${ }^{22}$, as the temperature rises, the solubility of $\mathrm{Al}$ in the primary $\alpha-\mathrm{Mg}$ phase increases and the binary $\mathrm{Mg}-9 \mathrm{Al}$ will experience a single $\alpha$ phase interval. So it can be suggested that the Al-rich eutectic $\beta$ phase can dissolve towards the primary $\alpha$ phase, resulting in the decrease of the $\beta$ phase amount. As discussed above, the $\beta$ phase amount between the dendrite arms (marked by $\mathrm{B}$ in Figure $3 \mathrm{a}$ ) is less than that between the dendrites (marked by A). So most of the $\beta$ phase between the arms can completely dissolves and even disappears. The disappearance must result in the mergence of the neighboring arms. The original equiaxed dendrites then become into near spheroidal particles due to this mergence. As the heating proceeds, the specimen's temperature reaches eutectic point and the residual eutectic then melts to form liquid phase (Figure 3b). Due to the difference in $\beta$ phase amount in these two regions, most of the residual $\beta$ phase should locate between the near spheroidal particles. So the formed liquid phase mostly also locates in these regions (Figure $3 b$ ). Through comparing Figure $3 a, b$, it can be found that the $\beta$ phase amount in the as-cast microstructure is obviously larger than the liquid phase amount in the microstructure heated for 2 minutes and the liquid phase within the primary particles is very little. These mean that the dissolution of $\beta$ phase towards the primary dendrites has certainly occurred. Furthermore, the original dendrites become into the compact near spheroidal particles (Figure 3b), which implies that the dendrite arms have merged due to the dissolution. So it can be concluded that the main event occurring during the initial heating period is the rapid coarsening of the equiaxed dendrites through mergence of their arms.

After the residual eutectic melts, the formed liquid phase then penetrates along the original grain boundaries or the grain boundaries directly melt due to the temperature rise, which leads the near spheroidal particles to separate from their neighboring particles. The microstructure changes into the individual polygonal particles that are separated by thin liquid layers. This process can be seen from Figure $3 b-\mathrm{d}$. In fact, the neighboring $\alpha-\mathrm{Mg}$ dendrites in the as-cast microstructure originally contact in some local zones due to the discontinuous distribution of the eutectic $\beta$ phase between them. The contact area must increase due to the dissolution of the $\beta$ phase during the coarsening stage. But the energy in either the original contact zones or the newly formed contact zones should be higher than that within the grains due to the difference in crystal orientation. Therefore, the first formed liquid then penetrates along

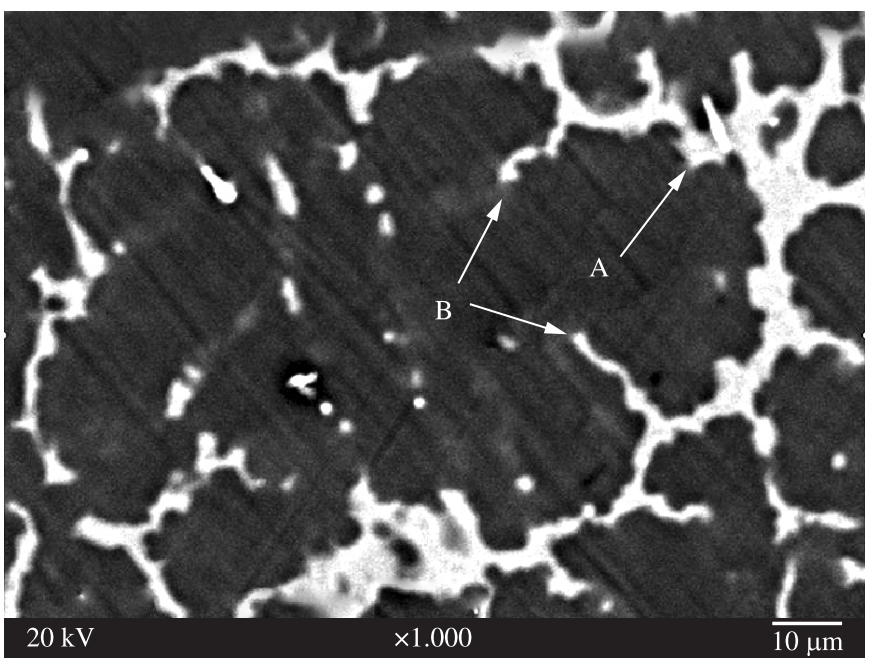

(a)

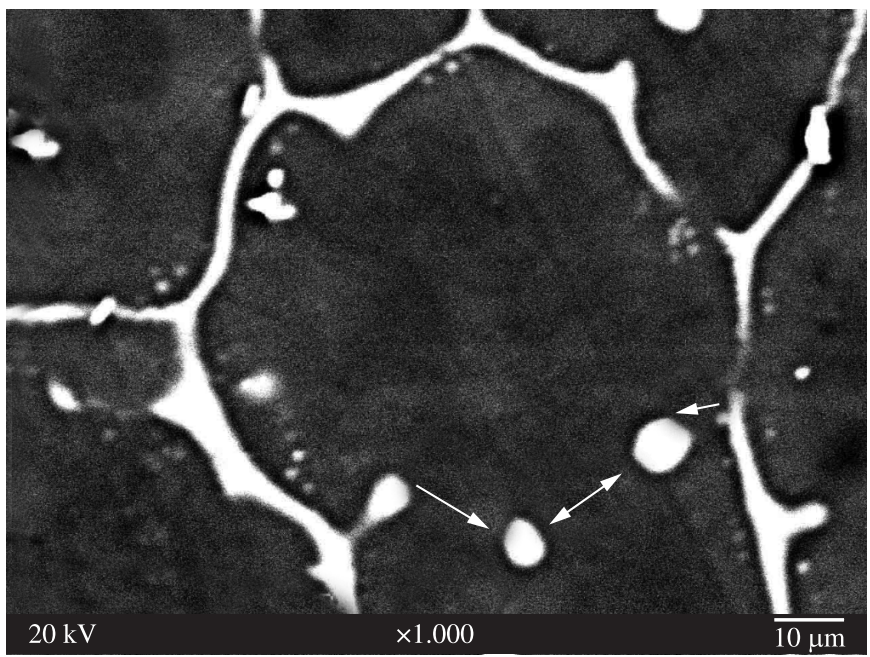

(c)

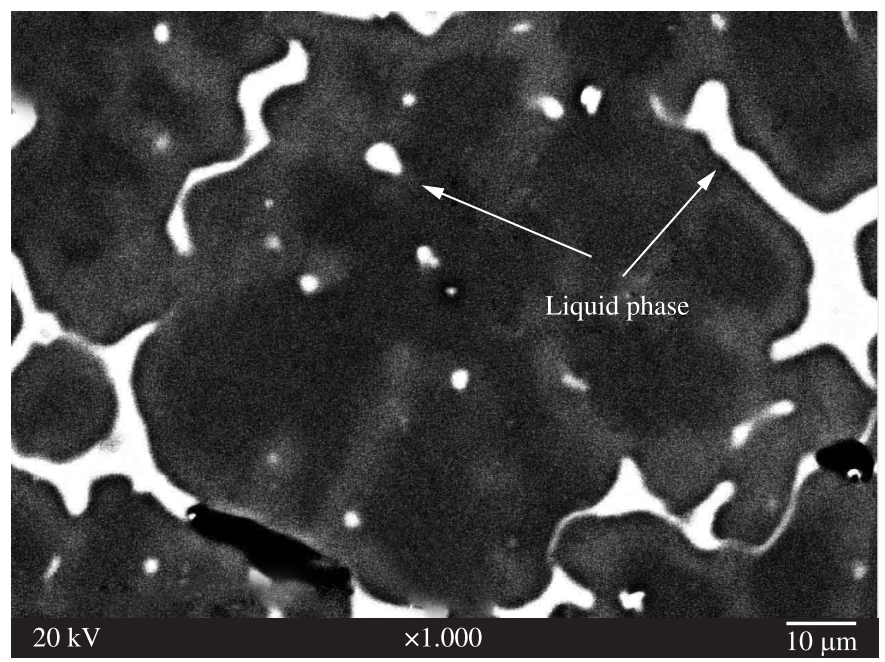

(b)

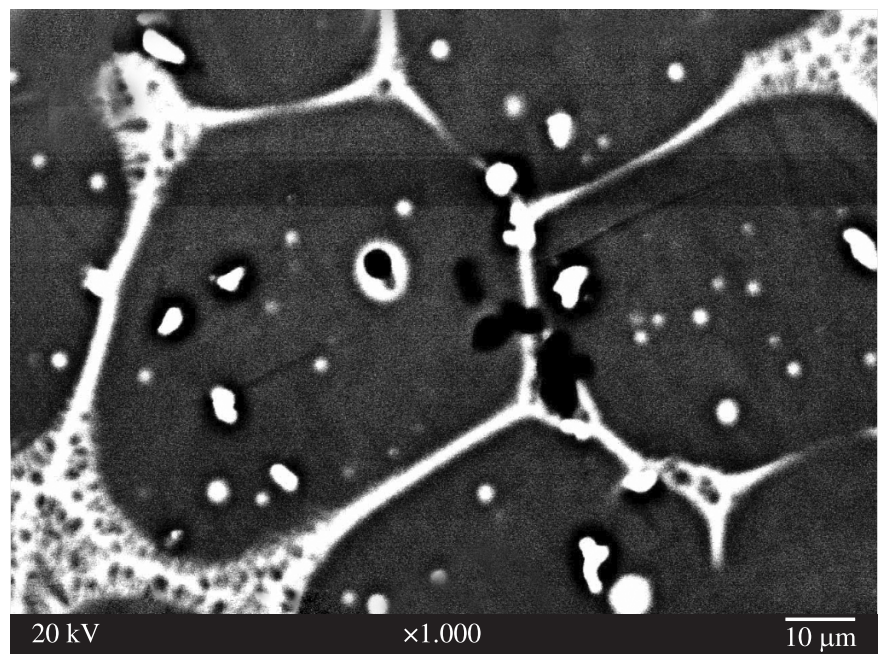

(d)

Figure 3. Microstructures of the refined AZ91D alloys heated for different durations at $580^{\circ} \mathrm{C}$ and then water-quenched. a) 0 minutes; b) 2 minutes; c) 3 minutes; and d) 10 minutes. 
these sites or these sites directly melt to separate the particles from their neighboring particles. As shown by Figure $3 \mathrm{c}$, the paths marked by arrows should be the penetration directions of the formed liquid phase along grain boundaries. So it can be proposed that the main phenomenon occurring after the coarsening stage is the structure separation resulted from the melting of the residual $\beta$ phase and subsequent penetration of the first formed liquid along the original grain boundaries or direct melting of the grain boundaries.

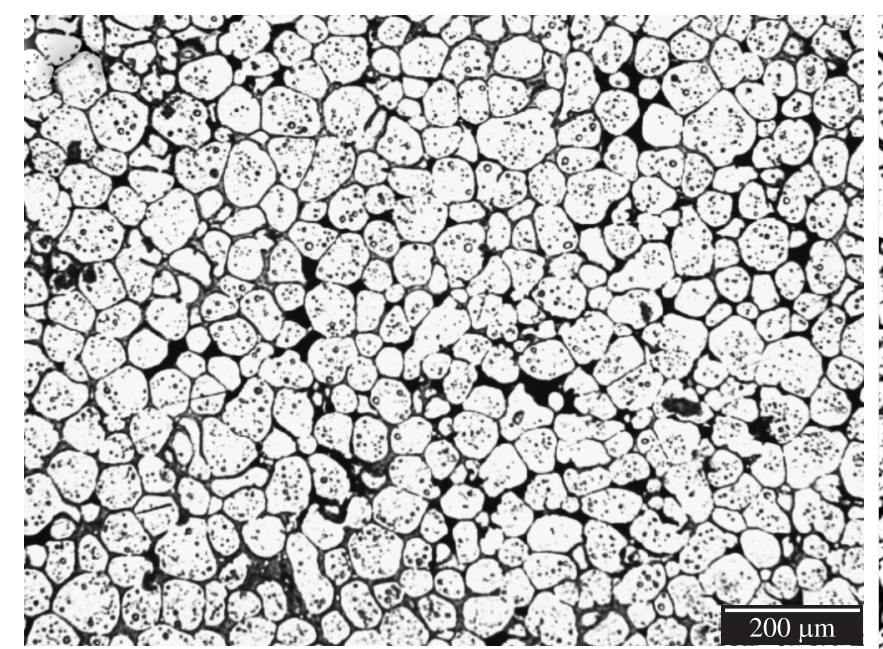

(a)

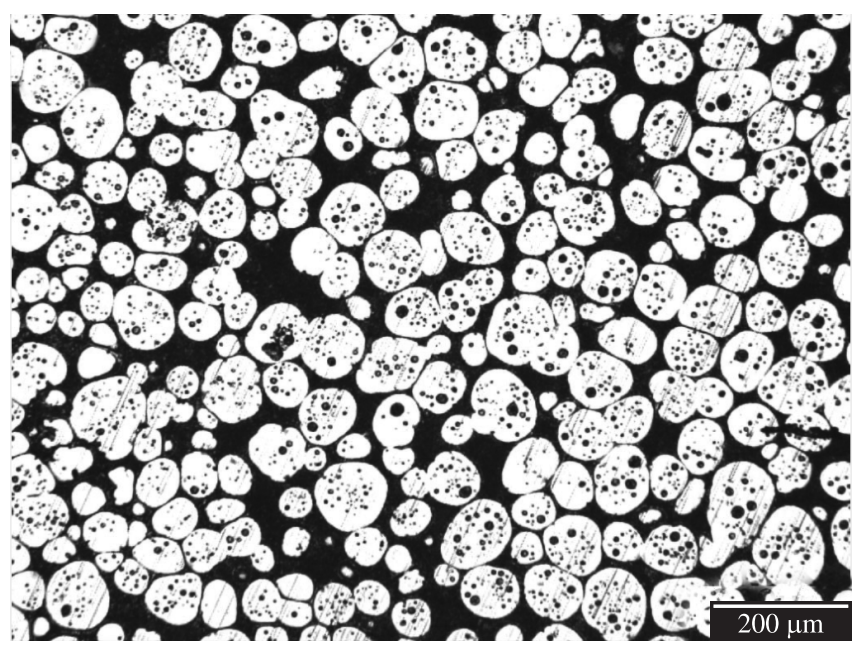

(c)

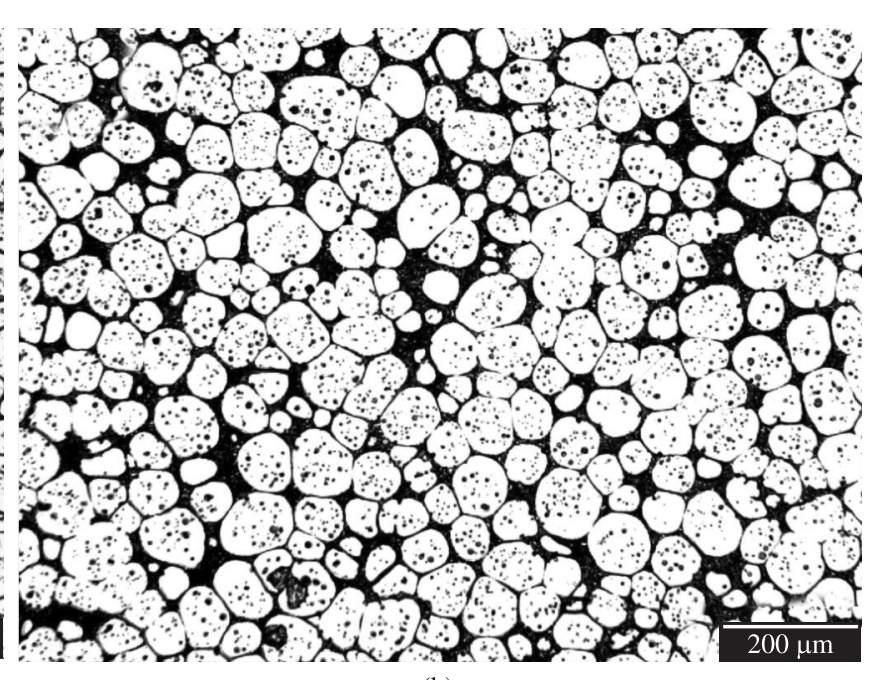

(b)

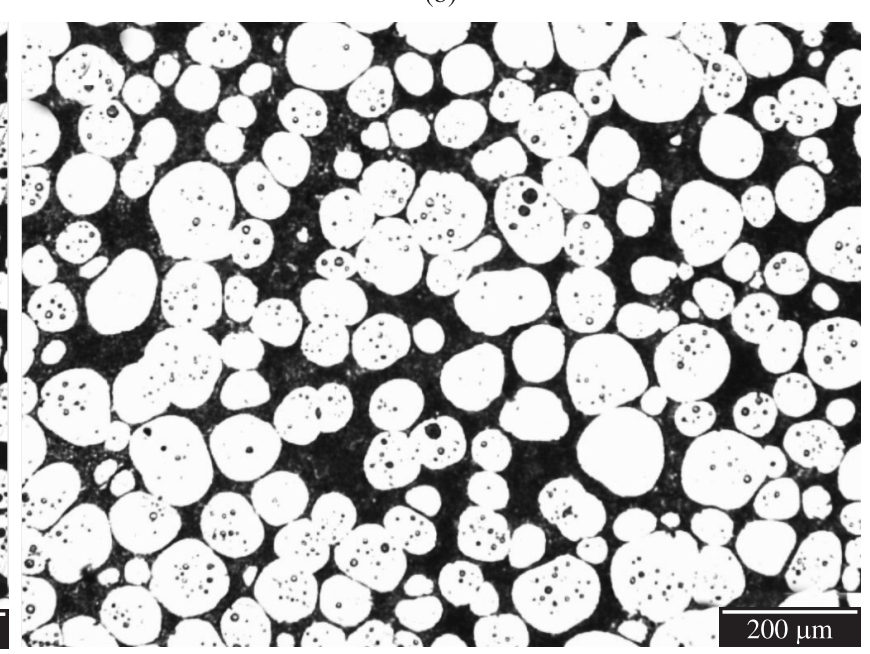

(d)

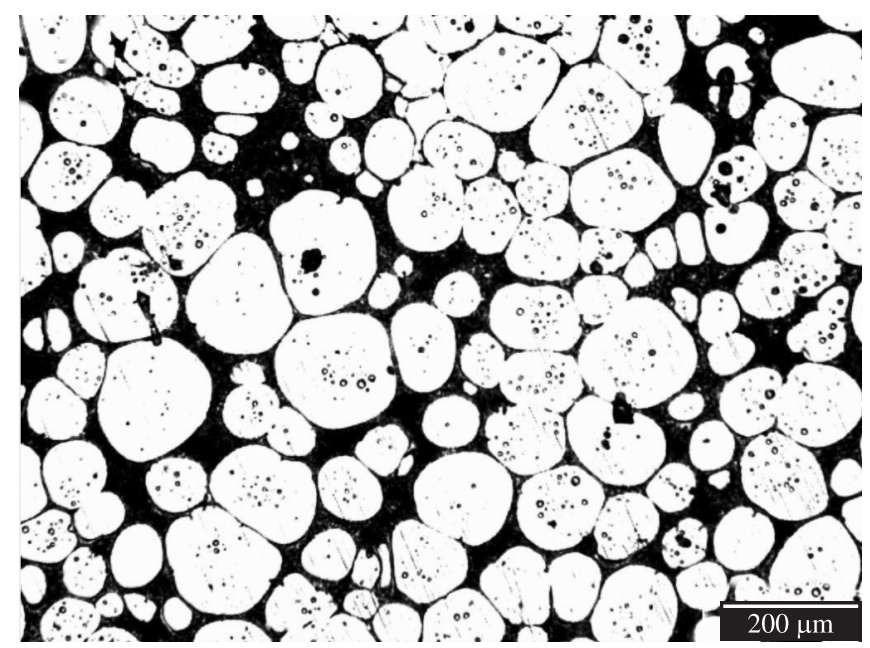

(e)

Figure 4. Microstructures of the refined AZ91D alloys heated for different durations at $580{ }^{\circ} \mathrm{C}$ and then water-quenched. a) 10 minutes; b) 20 minutes; c) 30 minutes; d) 60 minutes; and e) 90 minutes. 
The result indicates that the structure separation stage has almost completed after being heated for 10 minutes (Figure $3 \mathrm{~d}$ ). This can be more clearly demonstrated by Figure 4a: the microstructure is composed of uniform and small polygonal particles that are separated by thin liquid layers. Under this condition, the solid/ liquid interfacial energy should be very high because of the large solid/liquid interfacial area. Thus, the particles will coarsen during the subsequent heating driving by decreasing the interfacial energy (comparing Figure 4a-c). In addition, the particles simultaneously partially melt driving by increasing liquid amount due to the temperature rise. This partial melting should preferentially operate at the sharp corners or edges with large curvatures ${ }^{23}$, which does not only increase the liquid amount, but also leads the particles to become more and more spheroidal (comparing Figure $4 a-c)$. As a result, the microstructure evolves into small spheroidal particles that uniformly suspend in liquid phase when the specimen is heated for 30 minutes (Figure 4c). After then, the solid or liquid amount does not change obviously, which implies that the system reaches its solid-liquid equilibrium state. But the particle size continuously increases and their shape becomes more spheroidal (comparing Figure 4c-e). The quantitative variations of the particle size and shape factor during this period are shown by Figure 5. It thereby can be suggested that the microstructural evolution after being heated for 10 minutes can be divided into two stages, the spheroidization (accompanied by coarsening) stage of the polygonal particles due to their partial melting (from 10 to 30 minutes), and the final coarsening stage of the spheroidal particles (after 30 minutes). That is to say that the whole microstructural evolution of the AZ91D alloy includes four stages, the initial rapid coarsening, structure separation, spheroidization accompanied by coarsening and final coarsening.

As discussed above or shown by Figure 5, after being heated for 10 minutes, the formed particles all along coarsen and their size continuously increases. The coarsening mechanisms should be different during the different stages. Figure 4 a shows that the formed polygonal particle size and distance between them are quite small when the structure separation stage has just completed, and thus the solid/liquid interfacial energy should be very high. To promptly decrease the interfacial energy, the coalescence of neighboring particles frequently operates through boundary migration or particle rotation (that minimizes misorientation) ${ }^{24}$. As the coalescence

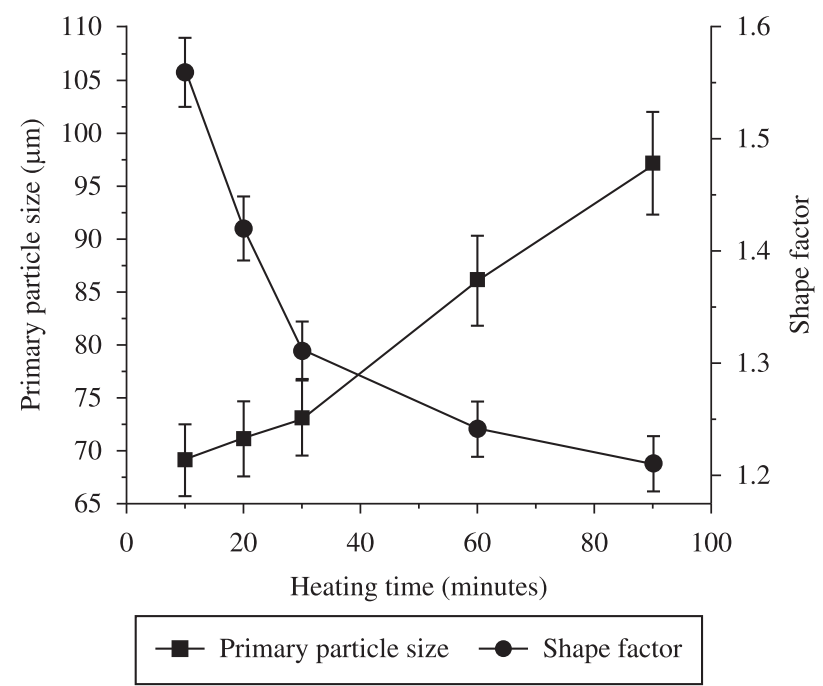

Figure 5. Variations of the primary particle size and shape factor with heating time. proceeds and the liquid amount increases, the interfacial energy is decreased and the distance between the particles is increased, and thus the coarsening from Ostwald ripening should play more and more important role. In the regime of Ostwald ripening, the semisolid system should be in its solid-liquid equilibrium state and the variation of particle size obeys the formula, $\mathrm{D}_{(\mathrm{t})}{ }^{3}-\mathrm{D}_{(0)}{ }^{3}=\mathrm{Kt}$, where $\mathrm{D}_{(\mathrm{t})}$ is the particle size at time $t, D_{(0)}$ is the initial particles size and $K^{(t)}$ is the coarsening rate constant ${ }^{25}$. The present result is shown by Figure 6 after being heated for 10 minutes. It shows that the variation during the period from 10 to 30 minutes does not obey this regime, but it does after 30 minutes. As discussed above, the system does not reach its solid-liquid equilibrium state until it is heated for 30 minutes. Therefore, these results further demonstrate that the coarsening during the period from 10 to 30 minutes results from coalescence and suggest that the coarsening after 30 minutes is attributed to Ostwald ripening. In addition, Ostwald ripening also includes the dissolution of edges and corners of the particles and subsequent reprecipitation at sunken zones $^{24,25}$. So the particles become more and more spheroidal and the shape factor continuously decreases during the final coarsening stage. Finally, it should be noted that these two coarsening mechanisms must simultaneously operate during the two stages, only their contributions are different.

The grain size of the refined as-cast AZ91D alloy is $79 \mu \mathrm{m}$ while the particle size in the semisolid microstructure (heated for 30 minutes) is $73 \mu \mathrm{m}$ (Figure 5). If one dendrite with size D evolves into one particle, the particle size D' can be calculated according to the formula:

$$
D^{\prime}=D \sqrt{f_{s}}
$$

where $f_{s}$ is solid fraction.

In the present work, the equilibrium solid fraction $\mathrm{f}_{\mathrm{s}}$ (after being heated for 30 minutes) is 0.61 , so the formed particle size should be $62 \mu \mathrm{m}$. Namely, the actual size of $73 \mu \mathrm{m}$ is larger than the calculated size. This implies that one spheroidal particle in the semisolid microstructure does not result from one equiaxed dendrite in the as-cast microstructure, but originates from two or more. However, for the microstructure that forms when the structure separation has just completed (heated for 10 minutes), the solid fraction $\mathrm{f}_{\mathrm{s}}$ is 0.73 , the calculated particle size is $68 \mu \mathrm{m}$. That is to say that the actual size of $69 \mu \mathrm{m}$ (Figure 5) is equivalent to the calculated size, which

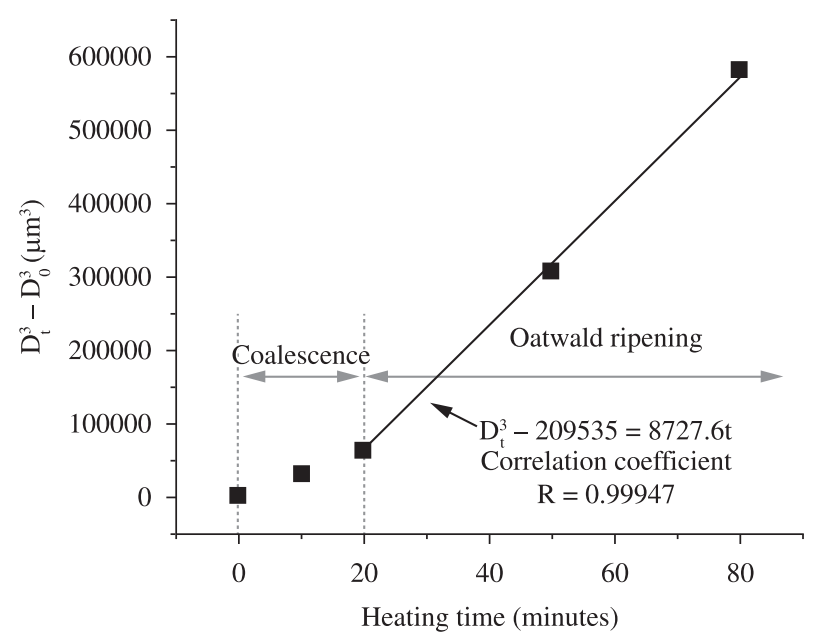

Figure 6. Cube of the primary particle size vs. heating time, taking 10 minutes as starting time, $\mathrm{t}=0$. 


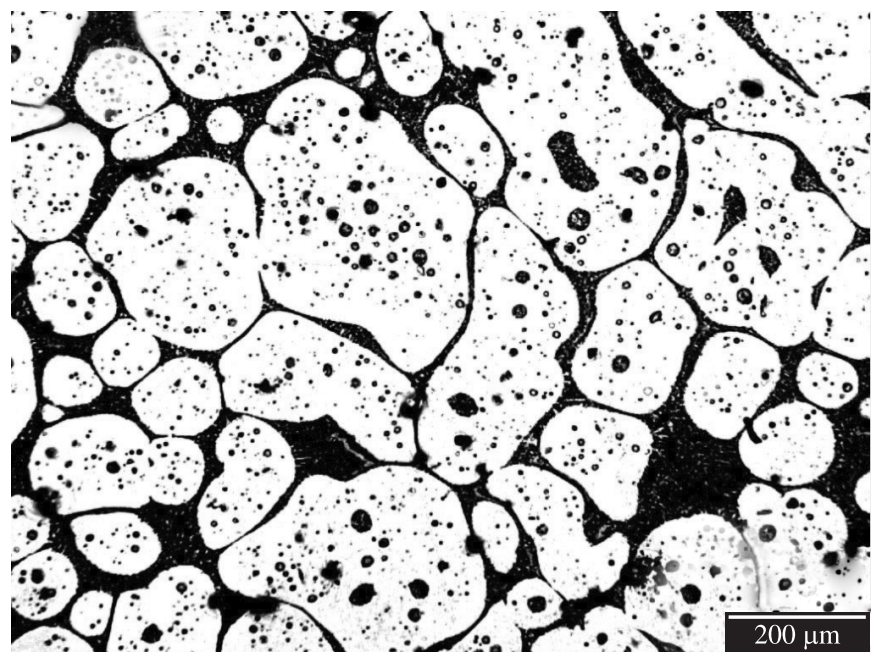

(a)

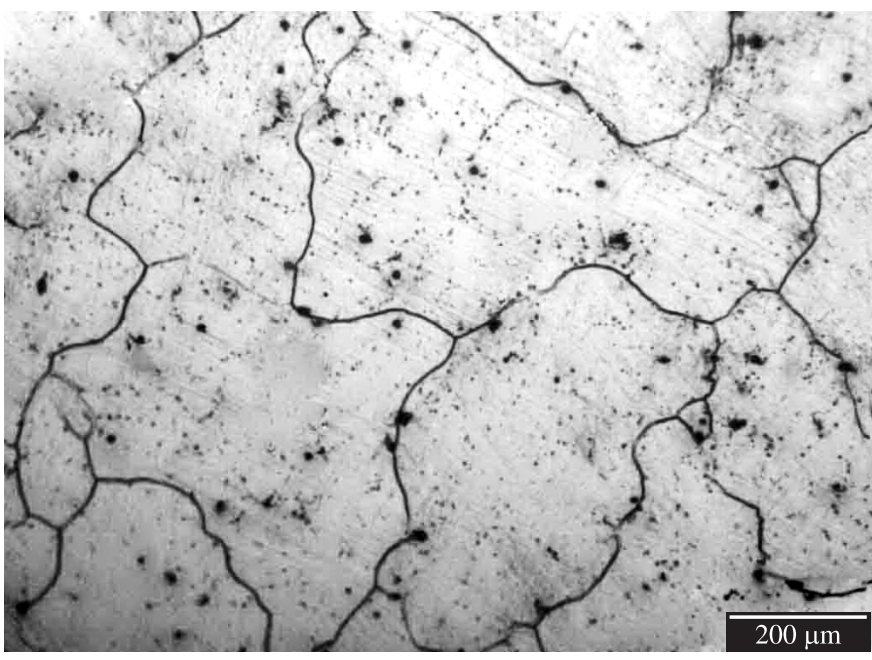

(b)

Figure 7. Microstructures of the unrefined AZ91D alloys after being: a) heated for 30 minutes at $580{ }^{\circ} \mathrm{C}$; and b) solutionized for 8 hours at $420{ }^{\circ} \mathrm{C}$.

means that one polygonal particle originates from one dendrite. All of these results further demonstrate the microstructural evolution process discussed above: the equiaxed dendrites become into near spheroidal particles through mergence of dendrite arms, and then they are separated each other by liquid layers due to the melting of residual eutectic and penetration by the firstly formed liquid along the original grain boundaries, and thus they develop into the individual polygonal particles. Following, two or more polygonal particles evolve into one spheroidal particle through spheroidization (partial melting) and coalescence. Namely, the coalescence does not only operate during the initial coarsening stage and the subsequent structure separation stage, but also does during the spheroidization stage.

It can be found that a semisolid microstructure with small and spheroidal primary particles available for thixoforming can be obtained after the refined AZ91D alloy is partially remelted. But for the unrefined alloy, as shown by Figure $7 \mathrm{a}$, the primary structures in the semisolid microstructure are very irregular and their size difference is quite large. Figure $7 \mathrm{~b}$ gives the microstructure after being solutionized for 8 hours at $420^{\circ} \mathrm{C}$, in which the particle size can reflect the as-cast alloy's grain size. Compared with Figure 7a, it can be seen that the primary structure size is obviously smaller than the grain size. The quantitative examination result indicates that the average primary structure size is $224 \mu \mathrm{m}$ while the average grain size is up to $422 \mu \mathrm{m}$. This means that one developed dendrite evolves into two or more primary structures after partial remelting, which is just contrary to the situation of the refined alloy.

Based on the above discussion, some important conclusions can be obtained. The microstructural evolution process during partial remelting of the refined AZ91D alloy can be divided into four stages: the initial rapid coarsening due to the dissolution of $\beta$ phase, structure separation resulted from the melting of residual $\beta$ phase and subsequent penetration of the firstly formed liquid along the original grain boundaries, spheroidization (accompanied by coarsening) ascribed to the partial melting (coalescence) and final coarsening owing to Ostwald ripening. Correspondingly, the fine equiaxed dendrites evolve into in turn of near spheroidal particles, small individual polygonal particles, small spheroidal particles and large spheroidal particles. One small spheroidal particle originates from two or more equiaxed dendrites through melting and coalescence. But for the unrefined alloy, one developed dendrite separates into

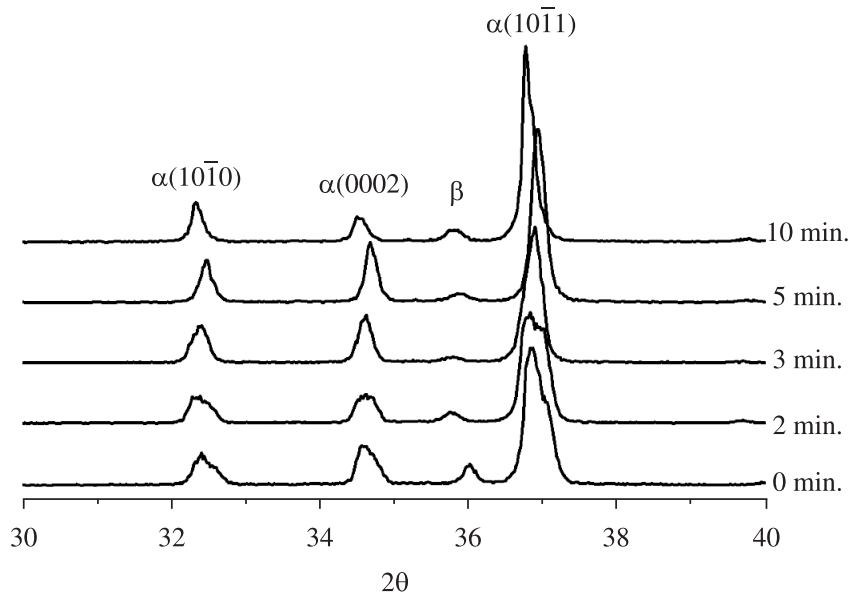

Figure 8. X-ray diffractograms of the refined AZ91D alloys heated at $580{ }^{\circ} \mathrm{C}$ for different durations and then water-quenched.

two or more primary structures with very irregular morphologies and large size difference.

\subsection{Phase transformations during partial remelting}

According to the above section, the first stage is the coarsening of dendrites through mergence of dendrite arms due to the dissolution of Al-rich $\beta$ phase towards the primary $\alpha$ phase. This dissolution leads the AZ91D alloy to have a tendency to experience a single $\alpha$ phase interval. Namely, the $\beta$ phase evolves into the $\alpha$ phase during this stage. In view of phase transformation, this process can be expressed by $\beta \rightarrow \alpha$. It is just because of this reaction that the $\beta$ phase amount decreases (comparing the corresponding diffraction intensities of $\beta$ phase shown in Figure 8) and the Al content in the primary $\alpha$ phase increases (Table 1). So it can be proposed that the initial coarsening is ascribed to the reaction of $\beta \rightarrow \alpha$.

When the specimen's temperature is up to eutectic point, the residual $\beta$ phase together with the eutectic $\alpha$ phase surrounding it melts to form liquid phase and this melting can be expressed by the inverse eutectic reaction, $\alpha+\beta \rightarrow \mathrm{L}$. Because some of the Mg-rich $\alpha$ phase simultaneously melt through this reaction, the Al content in the liquid phase is decreased compared with that of the $\beta$ phase (Table 1). 
Table 1. Chemical compositions (from EDS) of different structures of the AZ91D alloys heated at $580{ }^{\circ} \mathrm{C}$ for different durations and then water-quenched.

\begin{tabular}{cccr}
\hline \multirow{2}{*}{$\begin{array}{c}\text { Heating time } \\
\text { (minutes) }\end{array}$} & Structure & \multicolumn{2}{c}{ Composition (wt. (\%)) } \\
\cline { 3 - 4 } 0 & Primary $\alpha$ & 94.41 & 5.59 \\
& Eutectic $\beta$ & 82.56 & 17.44 \\
2 & Primary $\alpha$ & 93.82 & 6.18 \\
& Eutectic $\beta$ & 83.61 & 16.39 \\
3 & Primary $\alpha$ & 93.74 & 6.26 \\
& Liquid phase & 87.43 & 12.57 \\
\multirow{2}{*}{5} & Primary $\alpha$ & 92.99 & 7.01 \\
& Liquid phase & 88.19 & 11.81 \\
\multirow{2}{*}{10} & Primary $\alpha$ & 90.02 & 9.98 \\
& Liquid phase & 89.52 & 10.48 \\
\multirow{2}{*}{15} & Primary $\alpha$ & 89.26 & 10.74 \\
& Liquid phase & 89.96 & 10.04 \\
\multirow{2}{*}{20} & Primary $\alpha$ & 89.70 & 10.30 \\
& Liquid phase & 89.30 & 10.70 \\
\multirow{2}{*}{30} & Primary $\alpha$ & 90.27 & 9.73 \\
& Liquid phase & 88.42 & 11.58 \\
\hline
\end{tabular}

As the heating further proceeds, the main event is the penetration of the firstly formed liquid phase along the original grain boundaries or the melting of the boundaries. This process can be considered as the partial melting of the $\alpha$ phase because the residual eutectic has completely melted in a short time at eutectic temperature. Namely, the penetration and melting can be expressed by the reaction of $\alpha \rightarrow \mathrm{L}$. As a result of this reaction, the $\mathrm{Al}$ content in the liquid phase continuously decreases (comparing the values during the period of 2-10 minutes shown in Table 1). In addition, according to the Mg-Al binary phase diagram (Figure 1), the solubility of $\mathrm{Al}$ in the primary phase should increase as the specimen's temperature rises. So the $\mathrm{Al}$ atoms in the liquid phase diffuse towards the primary phase, not only resulting in the decrease of $\mathrm{Al}$ content in the liquid phase, but also resulting in the increase of $\mathrm{Al}$ content in the primary phase (Table 1). After being water-quenched, the liquid phase solidifies into the $\alpha$ phase and eutectic of $\alpha+\beta$ again, and the eutectic amount should increase with the increase of liquid amount. So the diffraction peak of the $\beta$ phase becomes more and more intensive again during the structure separation stage (Figure 8). Therefore, it can be concluded that the structure separation results from the reactions of $\alpha+\beta \rightarrow L$ and $\alpha \rightarrow L$.

Subsequently, the spheroidization accompanied by coarsening occurs. The essential of the spheroidization is the melting of edges and corners of the polygonal particles. So the phase transformation for the melting is still the reaction of $\alpha \rightarrow \mathrm{L}$. But for the coarsening resulted from coalescence, it does not involve any transformation. So the spheroidization stage accompanied by coarsening is owing to the reaction of $\alpha \rightarrow \mathrm{L}$. Also due to this reaction and the diffusion of $\mathrm{Al}$ atoms towards the primary particles, the $\mathrm{Al}$ contents in the liquid phase and primary particles are further decreased and increased respectively during the period of 10-15 minutes (Table 1). According to Figure $1^{22}$, the solubility of $\mathrm{Al}$ in the primary phase decreases as the temperature rises within the solidification interval. The Al content in the primary particles thereby insteadly decreases during the later period of this stage (15-30 minutes) while that in the liquid phase increases (Table 1).

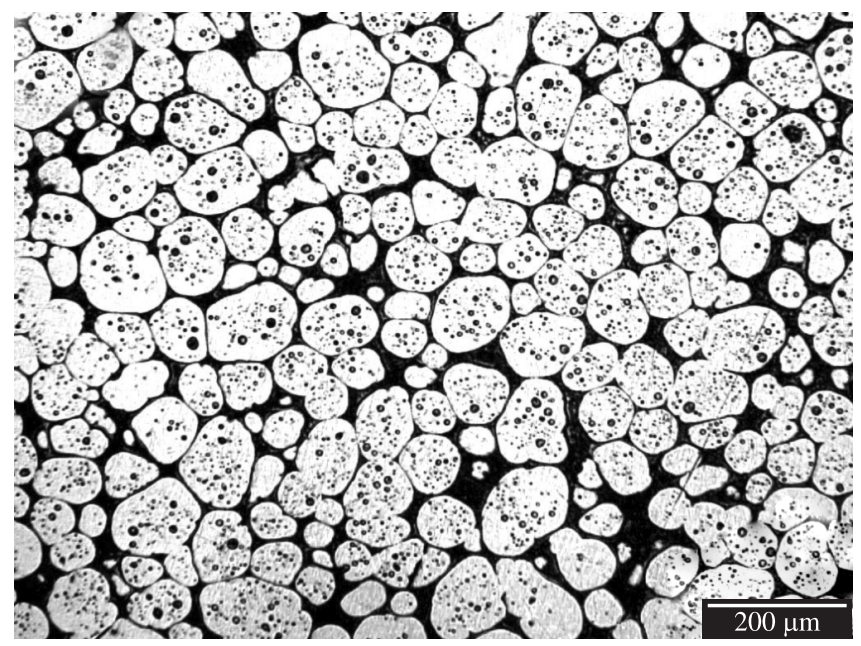

(a)

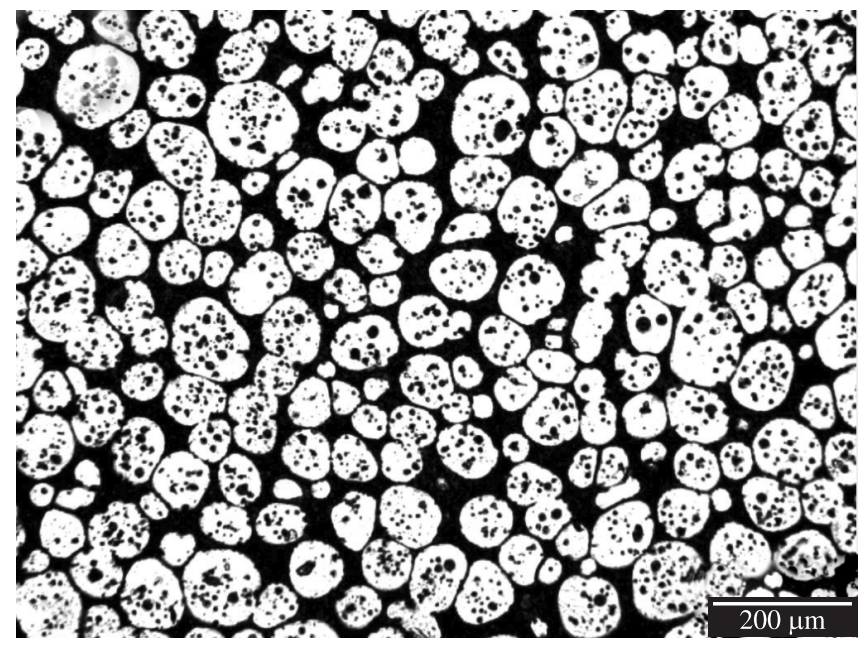

(b)

Figure 9. Microstructures of the refined AZ91D alloys heated for 30 minutes at: a) $570{ }^{\circ} \mathrm{C}$; and b) $590{ }^{\circ} \mathrm{C}$.

After the spheroidization, the final coarsening from Ostwald ripening operates. The essential of this stage is the dissolution and subsequent reprecipitation ${ }^{24,25}$. The amount of the dissolved $\alpha$ phase should be equal to that of the reprecipitated liquid phase because the solid or liquid fraction no longer changes in this stage. So the final coarsening behavior can be expressed by the two reverse reactions of $\alpha \rightarrow \mathrm{L}$ and $\mathrm{L} \rightarrow \alpha$.

Therefore, it can be concluded that the microstructural evolution can be well interpreted by the phase transformations occurring during this process. The initial rapid coarsening is due to the reaction of $\beta \rightarrow \alpha$, the structure separation results from the $\alpha+\beta \rightarrow L$ and $\alpha \rightarrow L$, the spheroidization is owing to the $\alpha \rightarrow \mathrm{L}$ and the final coarsening is ascribed to the two reverse reactions of $\alpha \rightarrow \mathrm{L}$ and $\mathrm{L} \rightarrow \alpha$.

\subsection{Effect of heating temperature on semisolid microstructure}

Heating temperature is well known to mainly affect the solid or liquid faction of a semisolid microstructure. In addition, this parameter is expected to influence the energy and diffusion ability of atoms, and thus affect the evolution rate and the primary particle size and shape factor. Figure 9 gives the semisolid microstructures heated 


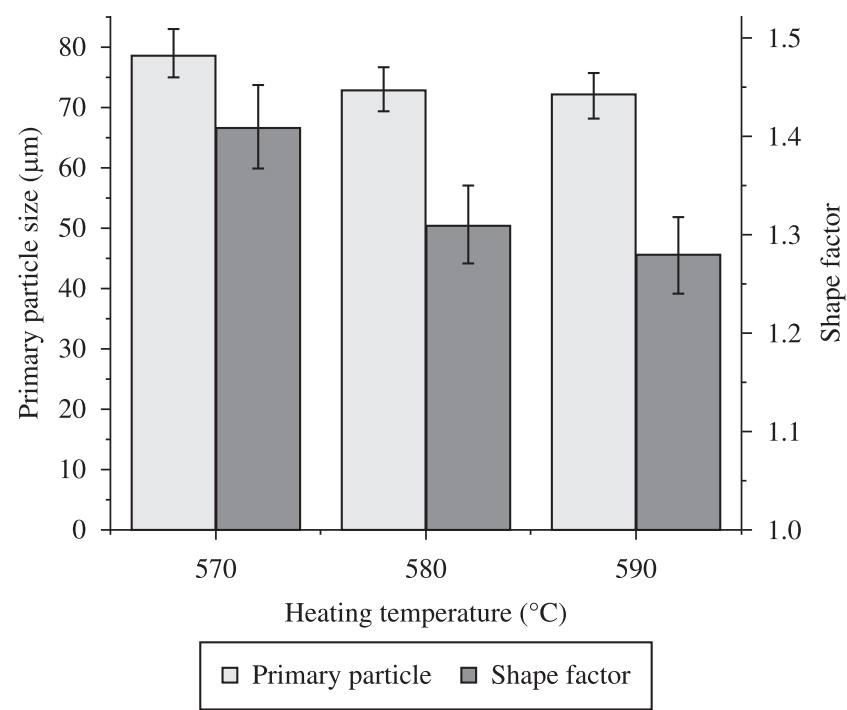

Figure 10. Primary particles sizes and shape factors of the refined AZ91DAlloys heated for 30 minutes at different temperatures.

at 570 and $590{ }^{\circ} \mathrm{C}$ for 30 minutes. Together with Figure $4 \mathrm{c}$, it can be found that the primary particle size decreases and their shape becomes more and more spheroidal as the heating temperature rises. These changes can be more clearly seen by the quantitative examination results shown by Figure 10 .

At low temperature, the partially remelted portion of the primary particles is relatively small. Furthermore, the distance between the particles is also short, and thus their coalescence is quite intensive during the spheroidization stage. So the primary particle size in the resulting semisolid microstructure is large and their shape is relatively irregular. As the temperature rises, both the energy and the diffusion ability of atoms increase. More part of the edges and corners of the particles with large curvature can melt, which does not only increase the distance and thus decrease their coalescence and size, but also leads them to become more spheroidal.

So it can be proposed that rising the heating temperature is beneficial for obtaining a semisolid microstructure with small and spheroidal primary particles. But it also generates too large amount of liquid phase and thus more and more advantages of thixoforming can be lost. Based on the microstructural evolution mechanisms discussed above, it can be suggested that increasing the heating rate, such as using induction heating method instead of the resistant heating approach, will decrease the time for coalescence, and thus a semisolid microstructure with desirable primary particles and low liquid fraction can be obtained.

\section{Conclusions}

1. A semisolid microstructure with small and spheroidal primary particles can be obtained after the AZ91D alloy refined by Al-Ti-B being partially remelted.

2. The microstructural evolution during partial remelting of the refined AZ91D alloy can be divided into four stages, the initial rapid coarsening, structure separation, spheroidization accompanied by coarsening and the final coarsening.

3. Two or more equiaxed dendrites in the as-cast microstructure evolve into one primary particle in the semisolid microstructure. The number decrease is attributed to the coalescence that occurs during the stage of spheroidization accompanied by coarsening.
4. One developed dendrite in the unrefined alloy will separate into two or more particles with irregular morphologies and large size difference during partial remelting.

5. There are good relations between the microstructural evolution stages and the phase transformations. The initial rapid coarsening results from the reaction of $\beta \rightarrow \alpha$, the structure separation is due to the $\alpha+\beta \rightarrow \mathrm{L}$ and $\alpha \rightarrow \mathrm{L}$, the spheroidization is attributed to the $\alpha \rightarrow \mathrm{L}$ and the final coarsening is ascribed to the two reverse reactions of $\alpha \rightarrow \mathrm{L}$ and $\mathrm{L} \rightarrow \alpha$.

6. Rising the heating temperature during partial remelting is beneficial for obtaining a semisolid microstructure with small and spheroidal primary particles.

\section{Acknowledgements}

The authors wish to express thanks to financial support from the National Basic Research Program of China (Grant No. G2010CB635106) and the Program for New Century Excellent Talents in University of China (Grant No. NCET-10-0023).

\section{References}

1. Eliezer D, Aghion E and Froes FH. The science and technique of magnesium alloy. Advanced Performance of Materials. 1998; 5:201-212. http://dx.doi.org/10.1023/A:1008682415141

2. Flemings MC. Behavior of metals and alloys in the semi-solid state. Metallurgical and Materials Transactions A. 1991; 22:957-981. http://dx.doi.org/10.1007/BF02661090

3. Kirkwood DH. Semisolid metal processing. International Materials Review. 1994; 39:173-189.

4. StJohn AV, Qian M, Easton MA, Cao P and Hildebrand Z. Grain refinement of magnesium alloys. Metallurgical and Materials Transactions A. 2005; 36:1669-1679. http://dx.doi.org/10.1007/s11661-005-0030-6

5. Easton MA, Schiffl A, Yao JY and Kaufmann H. Grain refinement of MgAl(-Mn) alloys by SiC additions. Scripta Materialia. 2006; 55:379-382. http://dx.doi.org/10.1016/j.scriptamat.2006.04.014

6. Chen TJ, Jiang XD, Ma Y, RQ Wang and Hao Y. Grain refinement of AZ91D magnesium alloy by $\mathrm{MgCO}_{3}$. Materials Research. 2011; 14:124-133. http://dx.doi.org/10.1590/S1516-14392011005000017

7. Chen TJ, Wang RQ, Ma Y and Hao Y. Grain refinement of AZ91D magnesium alloy by Al-Ti-B master alloy and its effects on mechanical properties. Materials and Design. In press. PMid:12194183. http://dx.doi. org/10.1016/j.matdes.2011.05.020

8. Fan Z. Semisolid metal processing. International Materials Review. 2002; 47:49-85. http://dx.doi.org/10.1179/095066001225001076

9. Nami B, Shabestari SG, Miresmaeili SM, Razavi H and Mirdamadi $\mathrm{SH}$. The effect of rare earth elements on the kinetics of the isothermal coarsening of the globular solid phase in semisolid AZ91 alloy produced via SIMA process. Journal of Alloys and Compounds. 2010; 489:570-575. http://dx.doi.org/10.1016/j.jallcom.2009.09.112

10. Zhang QQ, Cao ZY, Liu YB, Zhang YF, Zhang L, Zhang ML et al. Effect of asymmetrical deformation on the microstructure evolution of semisolid AZ91D alloy. Materials Science and Engineering A. 2008; 488:260-265. http://dx.doi.org/10.1016/j.msea.2007.12.002

11. Wang JG, Lin HQ, Wang HY and Jiang QC. Effects of different processing parameters on the semisolid microstructure of the AZ91D alloy during partial remelting. Journal of Alloys and Compounds. 2008; 466:98-105. http://dx.doi.org/10.1016/j.jallcom.2007.11.030

12. Wang JG, Lin HQ, Li YQ and Jiang QC. Effect of initial as-cast microstructure on semisolid microstructure of AZ91D alloy during the strain-induced melt activation process. Journal of Alloys and Compounds. 2008; 457:251-258. http://dx.doi.org/10.1016/j.jallcom.2007.03.051

13. Luo SJ, Chen Q and Zhao ZD. Effects of processing parameters on the microstructure of ECAE-formed AZ91D magnesium alloy in the semi-solid state. Journal of Alloys and Compounds. 2009; 477:602-607. http://dx.doi.org/10.1016/j.jallcom.2008.10.101 
14. Ji ZS, Hu ML, Sugiyama S and Yanagimoto J. Formation process of AZ31B semi-solid microstructures through strain-induced melt activation method. Materials Characterization. 2008; 59:905-911. http://dx.doi. org/10.1016/j.matchar.2007.07.015

15. Yang MB, Shen $J$ and Pan FS. Effect of TiC addition on semisolid isothermal heat treated microstructure of ZA84 magnesium alloy. Materials Science and Technology. 2009; 25:393-399. http://dx.doi. org/10.1179/174328408X353778

16. Zhao ZD, Chen Q, Kang F and Shu DY. Microstructural evolution and tensile mechanical properties of thixoformed AZ91D magnesium alloy with the addition of yttrium. Journal of Alloys and Compounds. 2009; 482:455-467. http://dx.doi.org/10.1016/j.jallcom.2009.04.059

17. Zhao ZD, Chen Q, Hu CK, Huang SH and Wang YQ. Near-liquidus forging, partial remelting and thixoforging of an AZ91D + Y magnesium alloy. Journal of Alloys and Compounds. 2009; 485:627-636. http://dx.doi. org/10.1016/j.jallcom.2009.06.053

18. Zhao ZD, Chen Q, Chao HY and Huang SH. Microstructural evolution and tensile mechanical properties of thixoforged ZK60-Y magnesium alloys produced by two different routes. Materials and Design. 2010, 31:1906-1916. http://dx.doi.org/10.1016/j.matdes.2009.10.056

19. Zha M, Wang HY, Xue PF, Li LL, Liu B and Jiang QC. Microstructural evolution of Mg-5Si-1 Al alloy during partial remelting. Journal of
Alloys and Compounds. 2009; 472:L18-L22. http://dx.doi.org/10.1016/j. jallcom.2008.05.016

20. Wang HY, Zha M, Liu B, Wang DM and Jiang QC. Microstructural evolution behavior of $\mathrm{Mg}-5 \mathrm{Si}-1 \mathrm{Al}$ alloy modified with $\mathrm{Sr}-\mathrm{Sb}$ during isothermal heat treatment. Journal of Alloys and Compounds. 2009; 480:L25-L28. http://dx.doi.org/10.1016/j.jallcom.2009.02.044

21. Yang MB, Pan FS, Cheng RJ and Bai L. Effect of semi-solid isothermal heat treatment on the microstructure of Mg-6A1-1Zn-0.7Si alloy. Journal of Materials Processing Technology. 2008; 206:374-381. http://dx.doi. org/10.1016/j.jmatprotec.2007.12.041

22. Massalski TB and Okamoto H. Binary Alloys Phase Diagrams. Ohio: ASM, Metal Park; 1990.

23. Chen PC, Zhu LM and Li Z. Fundamental of Metal Forming. Beijing: China Machine Press; 2003. 77 p.

24. Tzimas E and Zavaliangos A. Evolution of near-equiaxed microstructure in the semisolid state. Materials Science and Engineering A. 2000; 289:228-240. http://dx.doi.org/10.1016/S0921-5093(00)00908-4

25. Loue WR and Suéry M. Microstructural evolution during partial remelting of AlSi7Mg alloys. Materials Science and Engineering A. 1995; 203:1-13. http://dx.doi.org/10.1016/0921-5093(95)09861-5 